\title{
Comparison of sorption properties of black pepper of different fineness levels using selected models
}

\author{
Aneta Ocieczek $^{1 *}{ }^{\circledR}$, Tomasz Pukszta ${ }^{1}$, and Vitorina Chilumbo ${ }^{2}$ \\ ${ }^{1}$ Department of Commodity Science and Quality Management, Gdynia Maritime University, Morska 83, 81-225 Gdynia, Poland \\ ${ }^{2}$ Academy of Fishery and Marine Sciences, Moçâmedes, Namibe, Angola
}

Received September 11, 2019; accepted January 27, 2020

\begin{abstract}
The study assessed pepper's tendency to absorb water vapour from the environment. This property depends on its fineness level, and should be regarded as the basic factor determining its storage stability. The scope of the study included the determination of the water content and activity of the analysed material; the determination of adsorption isotherms at $20^{\circ} \mathrm{C}$ as well as a mathematical description of sorption isotherms using the Brunauer, Emmett, Teller, Guggenheim, Anderson, De Boer, and Peleg models. Another aim of the study was to assess these models for describing surface phenomena and to evaluate selected parameters of the pepper particle surface microstructure as well as the parameters characterizing the energy phenomena accompanying adsorption as factors used to predict stability during storage. An analysis of the results demonstrated that commercial samples of black pepper of different fineness levels were characterized by a different water content and activity. Pepper with a low fineness level exhibited a higher monomolecular layer volume and a greater sorption-specific surface area. The analysed pepper samples did not differ significantly in terms of porosity or capillary capacity. The GAB and Peleg models empirically described the determined sorption isotherms of ground black pepper in the full range of water activity very well.

Keyw ord s: sorption models, storage stability, fineness, surface phenomena, black pepper
\end{abstract}

\section{INTRODUCTION}

Black pepper (Piper nigrum L.) is one of the best known and most frequently used spices worldwide. Major world exporters of whole grain black pepper include Vietnam (39\% of the world's production), Indonesia (17\% of the

\footnotetext{
*Corresponding author e-mail: a.ocieczek@wpit.umg.edu.pl
}

world's production) and Brazil (16\% of the world's production), which indicates that the global popularity of the spice is associated with the need for long-distance transport. Therefore, the quality of this commodity is significantly affected by maritime transport conditions. According to the Observatory of Economic Complexity (OEC), the import of black pepper to Poland in 2017 amounted to $2.9 \%$ of the world's production, which accounted for $70 \%$ of the tonnage of Poland's import of spices and $80 \%$ of its value.

The quality of spices is undoubtedly determined by the cultivation and harvesting methods as well as by the packaging used and the storage methods and conditions applied, of which temperature, humidity and light exposure are of particular importance. An excessively high storage temperature can cause the rapid oxidation of essential oils, while excessively high humidity can promote the development of moulds (in particular) but also of bacterial flora. On the other hand, light, mainly in the UV range, can cause changes to the chemical components of the spice. As a result of these changes, the quality of the pepper may deteriorate significantly.

Dried spices are currently widely available, have a high degree of popularity and are among the spices, which are most frequently chosen by consumers. Their end user value is determined by both the time of harvesting and the method and conditions of drying, which are intended to reduce the water content to the minimum level set by the relevant

(C) 2020 Institute of Agrophysics, Polish Academy of Sciences 
standards (7-14\%). Food dehydration is among the most common processes applied to improve food stability as it significantly reduces microbial activity and minimizes enzymatic, chemical and physical changes during storage (Babetto et al, 2011; Triwahyudi et al., 2015). The dehydration of food prolongs its shelf-life while preserving its sensory characteristics, thus making it similar to fresh products (Sacilik and Unai, 2005; Triwahyudi et al., 2015).

Drying is probably one of the oldest methods of food preservation. It involves the removal of water until its content reaches a final level, which provides a product with microbiological stability and guarantees its expected storage life. In view of the phenomena, which occur after the completion of the drying process, it should be noted that a dry product is not in a thermodynamic equilibrium state (Newman and Zografi, 2019). Water activity and mobility are determined by water content and the temperature of the material. At higher water content values or higher temperatures, both the activity and mobility of molecules which are in a liquid state are high, and the material is susceptible to physical, chemical and biological degradation. For this reason, products should be dried to a final water content level that will guarantee their expected shelf-life (Lewicki, 2006). The provision of adequate barrier packaging materials for the storage of dried materials is of equal significance.

The quality of dried plant spices characterized by rich aroma and flavour is determined by their complex and varied chemical composition. These properties are constantly changing, primarily due to the surface phenomena occurring during their storage.

In the retail trade in Poland, two basic forms of black pepper are found: whole grained and ground. The process of pepper grinding expands its surface area, which may result in an increase in the dynamics of surface phenomena related to the effects of water vapour.

The most stable form of natural substances (including food) is the crystalline state, for example, the typical native form of starch granules. Slade and Levine (1991) found that solids in a glassy state also exhibit a favourable degree of stability. At least some of the dried products that are in a glassy state should remain in this state during storage. The change from a glassy state to a rubbery state at a constant water content occurs within a certain temperature range specific to each product, and is characterized by a mean temperature referred to as the glass-transition temperature $(T g)$. At a temperature lower than $T g$, the product is in a glassy state, whereas when the temperature is exceeded, the product transitions to a rubbery state, its structure disintegrates and the taste and aroma compounds are released (Roos, 1995). The $T g$ temperature level is closely correlated with water content, since water acts as a plasticizer, and an increase in its content contributes significantly to a reduction in $T g$. This means that a product remaining in a glassy state should be protected from water adsorption, e.g. by choosing the appropriate packaging material (Lewicki, 2006).

The concept of water content equilibrium is an important factor in the process of drying agricultural products. A knowledge of water content equilibrium may be used to determine the duration of product drying, the parameters of the drying equipment, and the costs associated with the drying process (Akanbi et al., 2006; Chowdhury et al., 2006; Triwahyudi et al., 2015). Research into the shelflife of food includes the application of static methods for determining the water content equilibrium, which involves leaving a sample to equilibrate in humid air, the degree of saturation is usually determined by an appropriate saturated chemical solution used to maintain a stable relative humidity environment.

Besides research into the equilibrium water content of food, research into the water activity of these products has been carried out. It has been known for more than half a century that the relative pressure of vapour above a product, related to this product's water activity, can play a role much more significant to the quality and shelf-life of the food than the total amount of water contained in it. The preference for water activity $\left(a_{w}\right)$ over water content as a reference parameter for most practical applications related to food processing and storage is a result of the fact that water activity is a determinant of microbial growth which affects most chemical, enzymatic and physical degradation reactions. It also has an effect on water migration in food; along with the equilibrium water content (water vapour sorption isotherms), it allows for the estimation of the monolayer used to determine the optimal water content of food products preserved by drying and is relatively straightforward to measure using modern techniques, its measurement is also non-invasive to the analysed product.

The aim of the study was to compare the sorption properties of black pepper of different fineness levels, which are a significant factor in the determination of hygroscopicity. The results obtained were used to compare the analysed samples in terms of storage stability. Another aim was to assess the usefulness of selected mathematical sorption models in order to describe the properties of pepper. Moreover, selected parameters of pepper particle surface microstructure as well as the parameters characterizing the energy phenomena accompanying adsorption are factors which may be used to predict stability during storage.

The achievement of the aim mentioned above was based on the verification of the research hypothesis, which assumed that the pepper fineness level has a significant effect on its sorptivity in terms of the interaction with water vapour present in the environment, which in turn has an influence on its hygroscopicity which determines stability during storage. 


\section{MATERIAL AND METHODS}

The study material comprised two commercial black pepper samples differing in fineness level, both were purchased at a store in the city of Gdańsk: "Prymat" brand black pepper of a high fineness level (D) and "Prymat" brand black pepper of a low fineness level $(\mathrm{G})$.

The water content was determined by thermal drying to a constant weight at a temperature of $373-378 \mathrm{~K}(100-$ $105^{\circ} \mathrm{C}$ ) under normal pressure.

Water activity $\left(a_{w}\right)$ at a temperature of $293.15 \mathrm{~K}\left(20^{\circ} \mathrm{C}\right)$ was determined with an accuracy of \pm 0.003 using an AquaLab apparatus (version AS4 2,14.0 2017, series 4TE and 4TEV, manufactured by Decagon Devices, Inc., Pullman, WA, USA).

Sorption isotherms were analysed by the static desiccator method using saturated solutions of the following substances: $\mathrm{NaOH} \mathrm{H}_{2} \mathrm{O}$ (0.0698); $\mathrm{LiCl} \mathrm{H}_{2} \mathrm{O}$ (0.1114); $\mathrm{KC}_{2} \mathrm{H}_{3} \mathrm{O}_{7} 1.5 \mathrm{H}_{2} \mathrm{O}(0.231) ; \mathrm{MgCl}_{2} 6 \mathrm{H}_{2} \mathrm{O}(0.3303) ; \mathrm{K}_{2} \mathrm{CO}_{3}$ $2 \mathrm{H}_{2} \mathrm{O}$ (0.440); $\mathrm{Na}_{2} \mathrm{Cr}_{2} \mathrm{O}_{7} 2 \mathrm{H}_{2} \mathrm{O}(0.548) ; \mathrm{KJ}(0.6986) ; \mathrm{NaCl}$ (0.7542); $\mathrm{KCl}(0.8513) ; \mathrm{KNO}_{3}(0.932) ; \mathrm{K}_{2} \mathrm{Cr}_{2} \mathrm{O}_{7}$ (0.9793). Testing was conducted within the environmental water activity range of 0.07 to 0.98 and at $293.15 \mathrm{~K}\left(20^{\circ} \mathrm{C}\right)$. The duration of the system equilibrium determination was 90 days from the time at which the samples were placed in desiccators. The samples incubated in desiccators with a water activity of more than 0.7 were protected from microfloral development. In the first phase of the experiment, pepper samples intended for the determination of sorption isotherms were placed in the amount of approximately $1 \mathrm{~g} \pm 0.1 \mathrm{mg}$ in weighing bottles with a diameter of approx. $35 \mathrm{~mm}$ in a desiccator containing $\mathrm{P}_{2} \mathrm{O}_{5}$ as a drying agent at room temperature for three weeks in order to minimize the moisture content $(\sim 2 \%)$ of the samples. The weights of the samples were then determined and before they were placed in desiccators with saturated solutions of appropriate substances. Based on the initial product weight (determined after 3 weeks of incubation in a desiccator with $\mathrm{P}_{2} \mathrm{O}_{5}$ ) and changes to the water content, the equilibrium water contents were calculated and adsorption isotherms were plotted using EXCEL 2010 software. The measurement of water activity in the samples was performed 90 days after placing them in desiccators using an AquaLab apparatus.

The diversity of the course of sorption isotherms within the entire $a_{w}$ range was statistically analysed using a $t$-Student test for the differences between the means for paired samples, with the differences at a significance level not exceeding a $P$ value of 0.05 , which is regarded as statistically significant.

The BET equation was in the following form:

$$
v=\frac{v_{m} C a_{w}}{\left(1-a_{w}\right)\left[1+(C-1) a_{w}\right]},
$$

where: $a_{w}$ - water activity $(-), v$ - equilibrium water content ( $\mathrm{g} \mathrm{H}_{2} \mathrm{O} 100 \mathrm{~g}^{-1}$ d.m.); $v_{m}$ - water content of the monolayer ( $\mathrm{g} \mathrm{H}_{2} \mathrm{O} 100 \mathrm{~g}^{-1}$ d.m.); $C$ - energy constant (Figura and Teixeira, 2007).
The GAB equation was in the following form:

$$
v=\frac{v_{m} C_{G} K a_{w}}{\left(1-K a_{w}\right)\left(1-K a_{w}+C_{G} K a_{w}\right)},
$$

where: $C_{G}$ - Guggenheim energy constant; $K-$ a constant, which corrects the properties of molecules forming the multilayer compared to the liquid phase (Figura and Teixeira, 2007).

Peleg's equation was in the form:

$$
v=A a_{w}^{C}+B a_{w}^{D},
$$

where: $A, B, C, D$-constants (Figura a nd Teixeira, 2007).

The parameters of selected equations were determined using non-linear regression and a Monte Carlo algorithm, which prevented the estimation process from being halted by the local minimum. The objective function was the minimization of the sum of squares deviation (SSD) (Ocieczek and Kostek, 2009). The calculations were performed using an Excel 2010 spreadsheet. Standard error values for the determined parameters of particular equations were estimated using the SolverAid macro command based on the Hessian matrix. The usefulness of the model for the description of experimental data were assessed based on the root mean square (RMS) expressed in \% (Pałacha and Sas, 2016):

$$
R M S=\sqrt{\frac{\sum\left(\frac{v_{e}-v_{o}}{v_{e}}\right)^{2}}{N}} 100 \%,
$$

where: $N$ - number of data, $v_{\mathrm{e}}$ - experimental equilibrium water content ( $\mathrm{g} \mathrm{H}_{2} \mathrm{O} 100 \mathrm{~g}^{-1}$ d.m.); $v_{\mathrm{o}}$ - forecasted equilibrium water content ( $\mathrm{g} \mathrm{H}_{2} \mathrm{O} 100 \mathrm{~g}^{-1}$ d.m.).

The specific surface area of adsorbent was calculated using the following equation:

$$
a_{s p}=\omega \frac{v_{m}}{M} N,
$$

where: $a_{s p}$ - specific surface area of sorption $\left(\mathrm{m}^{2} \mathrm{~g}^{-1}\right) ; N$ - Avogadro's number (6.023 $10^{23}$ molecules $\left.\mathrm{mol}^{-1}\right) ; M$ molecular mass of water $\left(18 \mathrm{~g} \mathrm{~mol}^{-1}\right) ; \omega$ - cross-sectional area of water $\left(1.0510^{-19} \mathrm{~m}^{2}\right.$ molecule $\left.{ }^{-1}\right)$ (Pérez-Alonso et al., 2006).

The size and volume of the capillaries of the material studied was determined for the condensation area using the Kelvin equation which assumes that their shape is cylindrical:

$$
\ln a_{w}=\frac{-2 \sigma V}{r_{k} R T},
$$

where: $\sigma$ - surface tension of liquid at temperature $T\left(\mathrm{~N} \mathrm{~m}^{-1}\right)$, $r_{k}$ - capillary radius $(\mathrm{nm}) ; R$ - universal gas constant $\left(\left(\mathrm{kJ}(\mathrm{mol} \mathrm{K})^{-1}\right) ; T\right.$ - process temperature $(\mathrm{K}), v$ - molar volume of the adsorbate $\left(\mathrm{m}^{3} \mathrm{~mol}^{-1}\right)$ (Figura and Teixeira, 2007). 


\section{RESULTS AND DISCUSSION}

Water contained in food is present in various fractions, as determined by the resultant force of interactions occurring between the components of a solid and water. The type and rate of the processes occurring in the product (and thus its shelf-life) are determined by the water fraction dominant in the product. Most methods for preserving food, including dried spices, involve a reduction in the amount of water contained in a product in order to decrease water activity.

Hygroscopicity is a characteristic of products with a high degree of dehydration which, while moving towards a dynamic equilibrium with the commonly more humid environment, absorb water. The hygroscopicity of each substance is primarily determined by the state of water present in this substance. The preliminary assessment of the hygroscopicity of pepper included the determination of water content and activity (Table 1).

Pepper with a low fineness level $(G)$ was characterized by a statistically significantly higher water content on a drymatter basis compared to pepper with a high fineness level (D) $(\mathrm{F}-$ Test $=0.9371 ; \mathrm{p}$ value $=0.000)$. It may be assumed that the reduction in water content was due to the grinding process accompanied by an increase in temperature and thus an increase in water vapour pressure that promotes the phenomenon of its desorption. Pepper of a low fineness level (G) was also characterized by a higher water activity, which was determined by its higher content (Table 1). At

Table 1. Water content and activity in the analysed black pepper samples

\begin{tabular}{clll}
\hline $\begin{array}{c}\text { Water content } \\
\left(\mathrm{g} \mathrm{H}_{2} \mathrm{O} 100 \mathrm{~g}^{-1} \text { d.m. }\right)\end{array}$ & $\mathrm{SD}$ & $\begin{array}{c}\text { Water } \\
\text { activity } \\
(-)\end{array}$ & $\mathrm{SD}$ \\
\hline \multirow{3}{*}{13.62} & Product G & & \\
& 0.33 & 0.680 & 0.003 \\
10.62 & Product D & & \\
& 0.35 & 0.445 & 0.003 \\
\hline
\end{tabular}

the same time, it should be emphasized that the identified water activity level prevented the product from maintaining microbiological stability (and thus storage stability as well) during storage.

The sorption properties of dried spices, i.e. products with hygroscopic properties, clearly determine their storage stability. Sorption isotherms are an effective tool for investigating these properties. A mathematical description of these curves using theoretical or empirical models in connection with a physical interpretation of the significance of parameters of some of these models is an appropriate approach to research into the inherent properties of all types of hygroscopic powders. Knowledge of the isotherm shape indicates the mechanism which determines the way water is bound in a product, the product sensitivity to water vapour in the atmosphere, and it also helps to predict changes during the storage of a particular product.

Adsorption isotherms of products D and G corresponded to type II in the classification proposed by Brunauer (Fig. 1), which is an unequivocal confirmation that the ground pepper particles are porous bodies.

In isotherms of this type, three areas expressing three mechanisms influencing the course of adsorption phenomenon can be distinguished. Isotherms of both analysed pepper samples (D) and (G) were constant within the entire water activity range, which indicates that no crystallization of any components occurred during the surface absorption of water vapour. In accordance with Gondek and Lewicki (2005), it was assumed that the isotherms of ground pepper would also not exhibit the hysteresis phenomenon either, whose presence is associated with at least the partial susceptibility of adsorbent particles to dissolution and the crystallization of sugars contained in it. Roman et al. (1982) and Tsami et al. (1990) are of the opinion that the water activity value at which hysteresis is observed is inversely proportional to the sugar content. Ground black pepper is primarily characterized by the presence of crystalline starch with a negligible number of amorphous areas determined by the peripheral damage to starch granules during grain

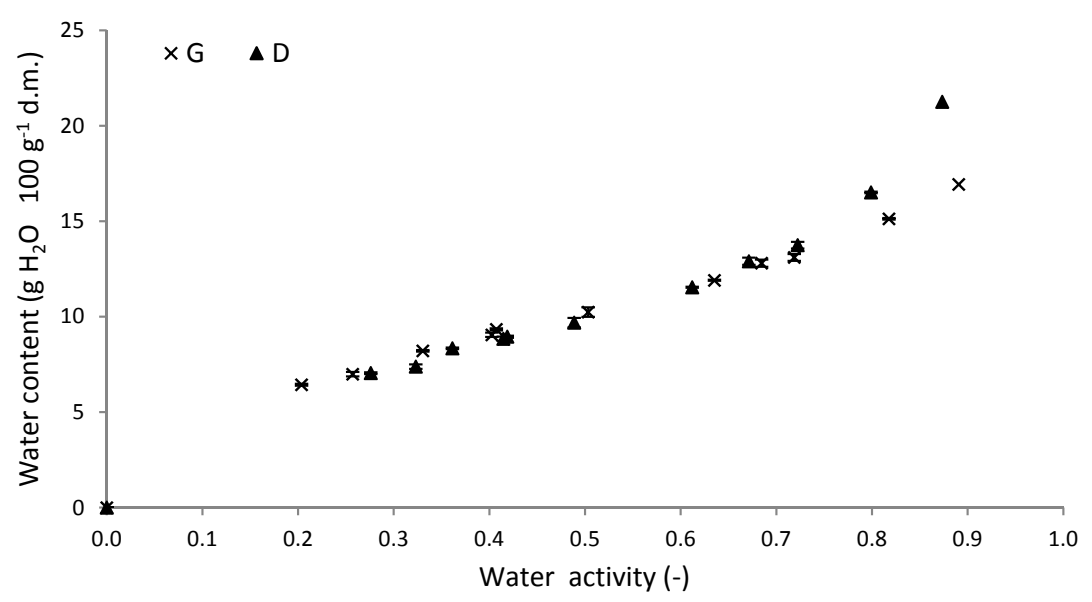

Fig. 1. Water vapour adsorption isotherms determined at $20^{\circ} \mathrm{C}$ on both black pepper samples $(\mathrm{G}$ and $\mathrm{D})$. 
grinding. Nevertheless, it should be taken into account that grinding leading to damage in "crystalline" materials to which natural starches belong can result in an increase in hygroscopicity, and thus contribute to a reduction in physicochemical stability. This, in turn, can potentially decrease storage shelf-life (Newman and Zografi, 2019).

Ahlneck and Zografi (1990) demonstrated that heavily dehydrated materials characterized by the presence of at least a partially amorphous and, thus, physically differentiated structure of the matrix, are prone to intense water absorption particularly by these especially amorphous areas. In such a situation, even a seemingly insignificant increase in water content will actually form a water pool of importance to product stability, located in a small area of the sample, which is referred to as the "amplification" of the water effect. Even a statistically insignificant increase in the water amount can then change the molecular mobility in these unstructured regions and initiate changes that result in both physical and chemical instability (Buckton, 1997) and, consequently, reduce the shelf-life or determine the differentiation of technological characteristics.

The course of the isotherms of both analysed pepper samples was particularly similar at the sites corresponding to monomolecular adsorption $\left(\mathrm{t}_{\text {calc. }}=1.803 ; \mathrm{t}_{\text {crit. }}=2.228\right)$ and multilayer adsorption $\left(t_{\text {calc. }}=2.153 ; t_{\text {crit. }}=2.228\right)$, while differing, though to a statistically insignificant extent, $\left(t_{\text {calc. }}=1.674 ; t_{\text {crit. }}=2.228\right)$ within the capillary condensation area. It may be assumed that greater differences in the course of both sorption isotherms in the capillary condensation area were due to the expansion of the pepper surface resulting from its different fineness levels and not due to the differences in the chemical composition of the powders.

While aiming at expressing the relationship between water activity and its content in food in mathematical terms, various regression models have been developed. The parameters of these models are partial regression coefficients, which describe each of the three sorption isotherm zones. In many cases, known models that exhibit a usefulness for describing the sorption properties of only one particular food product are ineffective for describing others. Some of the models also exhibit an adequate predictive power only within certain water activity ranges (Andrade et al., 2011).

Some of the mathematical sorption isotherm models were derived from the theoretical foundations of the adsorption mechanism description, while others are either empirical in nature or simplified versions of more complex models. The following are most commonly used to describe sorption phenomenon in food products: the Langmuir equation, the BET equation, the GAB model, the Oswin model, the Smith model, the Halsey model, the Henderson model, the Iglesias-Chirife equation and the Peleg model (Sahin and Gülüm, 2006). The criteria taken into account in the selection of the most suitable sorption model include the degree of fitting to experimental data and the simplicity of the model.

Knowledge of the shape and location of water adsorption isotherms in mathematical terms allows for, in the case of theoretical models, the estimation of selected parameters of the material surface microstructure and energy phenomena accompanying the sorption process. To this end, BET and GAB models whose parameters have a specific physical meaning are applied. The determination of the monolayer volume, which is a parameter of both the BET and GAB model, enables the estimation of the specific sorption capacity. On the other hand, the determination of the energy constant serves to identify the difference between the chemical potential of the particles of adsorbate in the pure state and in the first adsorption layer (BET) or the difference between the chemical potential of the particles of adsorbate in the first adsorption layer and in the higher layers (GAB) (Timmermann et al., 2001). These parameters are regarded as useful for predicting the optimal storage conditions and the storage stability of (particularly dehydrated) food.

The BET and GAB equations are an extension of the multimolecular concept proposed by Langmuir and they allow for a description of sigmoidal isotherms commonly observed in the context of food and other material of biological origin.

The BET equation is the most frequently applied model used to investigate surface phenomena occurring in food, and is a major breakthrough in the interpretation of multilayer sorption isotherms, particularly type II and III. Moreover, it is an effective method for estimating the amount of water bound to the polar sites of dehydrated food. This model assumes that the sigmoidal shape of the isotherm is due to multilayer adsorption. According to this assumption, each adsorbed molecule becomes an adsorption centre for the next adsorbate molecule. The forces occurring during the formation of subsequent layers are analogous to those, which cause vapour-to-liquid condensation. The model can be used to calculate the content of water bound in the monomolecular layer on the assumption that the adsorption surface is homogeneous and that no interactions take place between the adsorbed water molecules. At the same time, it should be stressed that the BET equation, regardless of whether it has been determined by the analytical or numerical method, accurately describes the course of the sorption phenomenon within a limited water activity range (0.05-0.5) (Rizvi, 1995).

Figures $2 \mathrm{a}$ and $\mathrm{b}$ show the course of the sorption isotherms for both tested black pepper samples, empirically determined and theoretically calculated based on the BET equation. A graphic interpretation was applied to the entire water activity range to reflect the limitations of the BET equation in the description of surface phenomena to a narrower range. 
a

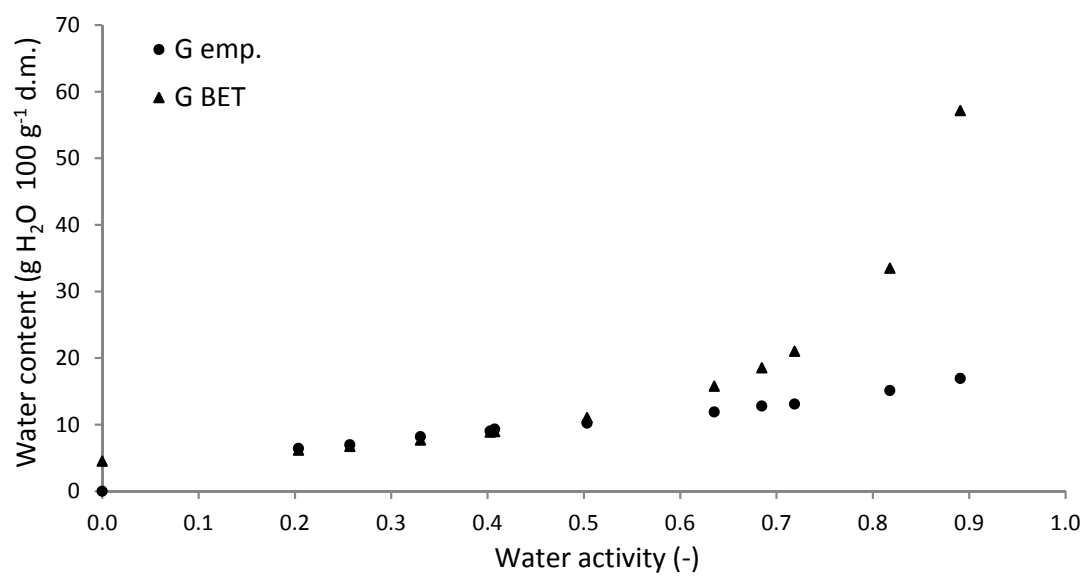

b

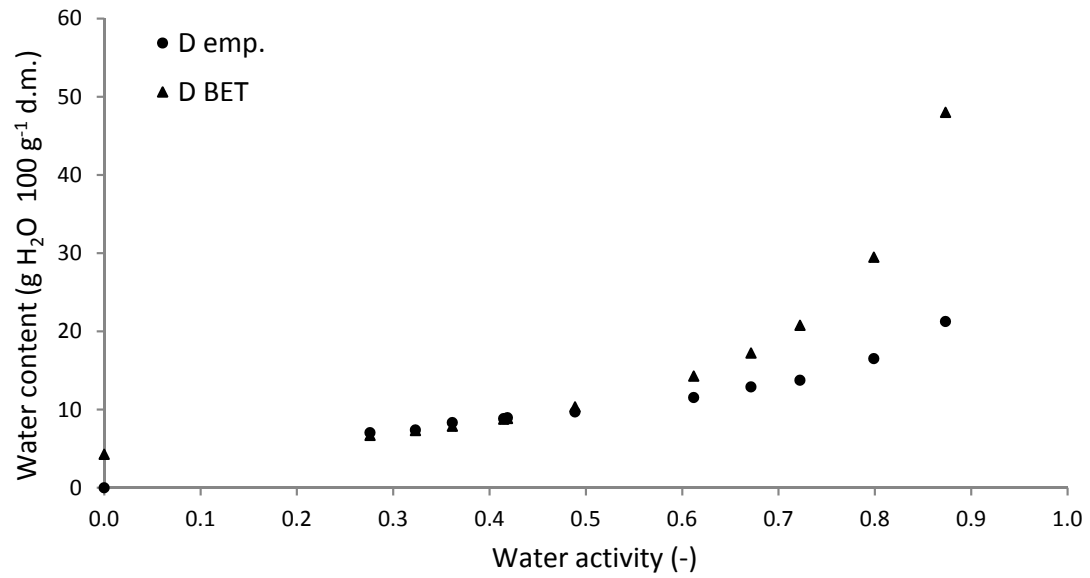

Fig. 2. Empirical and theoretical (BET) isotherm of water vapour adsorption by: a - pepper G and b - pepper D particles.

Considering the limitations of the BET model, its parameters were estimated within the range indicated as those corresponding to a good fit to the empirical data. The values of the deviation square sums and of the errors with which they were determined indicate that the BET model accurately describes the process of water vapour adsorption on the ground black pepper surfaces and with a similar accuracy, irrespective of the sample fineness level (Table 2). This finding is also confirmed by the determined RMS values, which indicate that the BET model is characterized by a very good fit to empirical data (RMS values lower than 10\%).

Table 2. BET equation parameters of the analysed black pepper samples

\begin{tabular}{lcc}
\hline Parameters & Product G & Product D \\
\hline SSD (-) & $1.2425 \pm 0.6436$ & $0.7849 \pm 0.5115$ \\
RMS (\%) & 5.0439 & 4.1476 \\
$v_{m}\left(\mathrm{~g} \mathrm{H}_{2} \mathrm{O} 100 \mathrm{~g} \mathrm{~g}^{-1}\right.$ d.m.) & $3.154 \pm 1.221$ & $2.901 \pm 1.297$ \\
$C(-)$ & $1.431 \pm 0.375$ & $1.478 \pm 0.442$ \\
\hline
\end{tabular}

The water content corresponding to the monomolecular layer is the minimum and, at the same time, the optimal water content due to the durability of the dried product. Water in an amount equivalent to the monomolecular coating is characterized by low activity, does not freeze at $-40^{\circ} \mathrm{C}$, is not available as a solvent, has no softening properties and does not contribute to hydrolytic degradation but rather protects against oxidative changes both in the aqueous and lipid phases. A knowledge of this parameter allows for the determination of the final drying point and thus, the optimization of the costs of technological processes and it is also of significance in food storage and transport (Gal, 1983). According to Karel (1975), most food products are characterized by a monomolecular layer ranging from 4 to $11 \mathrm{~kg}$ per $100 \mathrm{~kg}$ of dry matter. The monolayer $\left(v_{m}\right)$ is regarded as an indicator of the availability of polar sites for water vapour irrespective of which component is a source of hydrophilic groups. The $v_{m}$ is determined by the number of particular components, which are abundant in polar sites and by their physical state, by determining the amount of water, which is firmly bound to the food matrix (Ocieczek, 2012). Excess water, as compared to the monomolecular layer, results in a critical water content which, if exceeded, 
causes various undesirable changes in the product that impair its quality and enable microbial development. The monolayer values determined are based on a BET transformation ranging from 2.90 to $3.15 \mathrm{~g} \mathrm{H}_{2} \mathrm{O}$ per $100 \mathrm{~g}$ of dry matter of the product, and were lower than those determined by Karel (1975). The differences in monolayer values for the analysed pepper samples may indicate the differentiation of the dry matrix state, which is determined by the fineness level. The structure of starch granules, which are a dominant component of black pepper grains, may undergo changes due to their disaggregation during grinding. The results obtained indicate that the differences in monolayer extension should not only be related to the pepper grain fineness level. It appears that the state of the particles formed in this way (which are primarily comprised of starch granules of different levels of damage to the semi-crystalline structure due to the applied grinding method) is also of significance. The presence of amorphous areas formed in this way can intensify the phenomenon of surface absorption, which results in a local increase in hygroscopicity and the "amplification" of the water effect. This phenomenon was concisely described by Buckton (1997).

The estimated values of the monolayer $v_{m}$ provided a basis for the calculation of the specific sorption surface, which ranged from 101.9 (D) to $110.8 \mathrm{~m}^{2} \mathrm{~g}^{-1}$ (G). On the other hand, the BET model was not applied to calculate the general capillary capacity because the model exhibits a constant tendency towards a significant over-estimation of the equilibrium water content after exceeding the point corresponding to the beginning of the capillary condensation phenomenon (Fig. 2a and b). This area provides a basis for this estimation.

The energy constant $C$ reflects the difference between the enthalpy of desorption from the monolayer and the enthalpy of fluid adsorbent evaporation. Low constant $C$ values indicate that the process observed on the surface of analysed pepper samples was by nature a physical adsorption process.

Another theoretical model used to describe both the sorption properties of black pepper and selected surface microstructure parameters was the GAB model, which has many advantages over other models. One of the key properties of the GAB model is that it has a realistic theoretical background, because it is an improved version of the physical adsorption theory by Langmuir and includes aspects of the BET model. The GAB model is an extension of the multilayer adsorption theory and a modified version of the BET model. It postulates that the state of sorbate particles in the second layer is identical to that in higher layers but differs from the liquid state. The water molecules, which form the second and subsequent layers, usually fill small capillaries and are more loosely bound to the solid matrix than the monomolecular water layer. Thus, they contribute to the progressive loosening of the structure and expose additional polar sites. This fraction of water found in food products is perceived to be a continuous transition from bound water to free water. In order to provide a description of the phenomenon of sorption on a solid surface that is more precise than the BET model, the GAB model contains a third constant $(K)$ which specifies the chemical potential difference between the molecules forming the multilayer (described as the 2nd area of the sorption isotherm) and the chemically pure water molecules.

The advantage of the GAB model is that a physical interpretation related to the course of the sorption phenomenon was assigned to its parameters. It also enabled an analysis of the effects of temperature on isotherms using Arrhenius-type equations (Al-Muhtaseb et al., 2002). A disadvantage of the GAB model is that it understates the predicted equilibrium water contents corresponding to high levels $\left(a_{w}>0.93\right)$ of water activity (Fig. 3a and b). Above these values, the GAB model loses its great predictive power. It should therefore be stressed that the method using saturated substance solutions in the determination of sorption isotherms should not be applied within the full water activity range if the data are to be subject to a mathematical description of the sorption curve using the GAB model. The GAB equation parameters identified while taking into account the above-described limitations along with the error values are provided in Table 3 .

A comparison of the SSD and RMS values allows for the conclusion to be reached that the GAB model, by describing the course of the phenomenon of sorption on the analysed pepper sample surfaces within a wider range $a_{w}$ compared to the BET model, also allowed for the empirical data to be reflected better than by using the BET model. This is because it is assumed that the root mean square (RMS) value at a level lower than $10 \%$ indicates a good fit of the model to sorption data within the entire analysed range $a_{w}$ (Pałacha and Sas, 2016).

The $v_{m}$ values determined based on the GAB model were higher than those for the BET model, and fell within the range of 6.41 to $8.03 \mathrm{~g} \mathrm{H}_{2} \mathrm{O}$ per $100 \mathrm{~g}$ of dry matter of the product, which corresponded to the range provided by Karel (1975).

The Guggenheim energy constant $C_{G}$ ranged from 16.59 for pepper with large particles $(G)$ to 26.17 for pepper with small particles (D). These values indicate that the GAB model describes the results of the study very well as the $C_{G}$ parameter took on values greater than 5.67, which, according to Lewicki (1997), indicates that the model and its parameters were properly selected for the description of the empirical data. In turn, according to Diosady et al. (1996), strong exothermic interactions between the adsorbent and the adsorbate decrease the process temperature and increase the $C_{G}$ value. In the context of these records, it may be concluded that the process of surface water absorption for both analysed black pepper samples was physical in nature. 


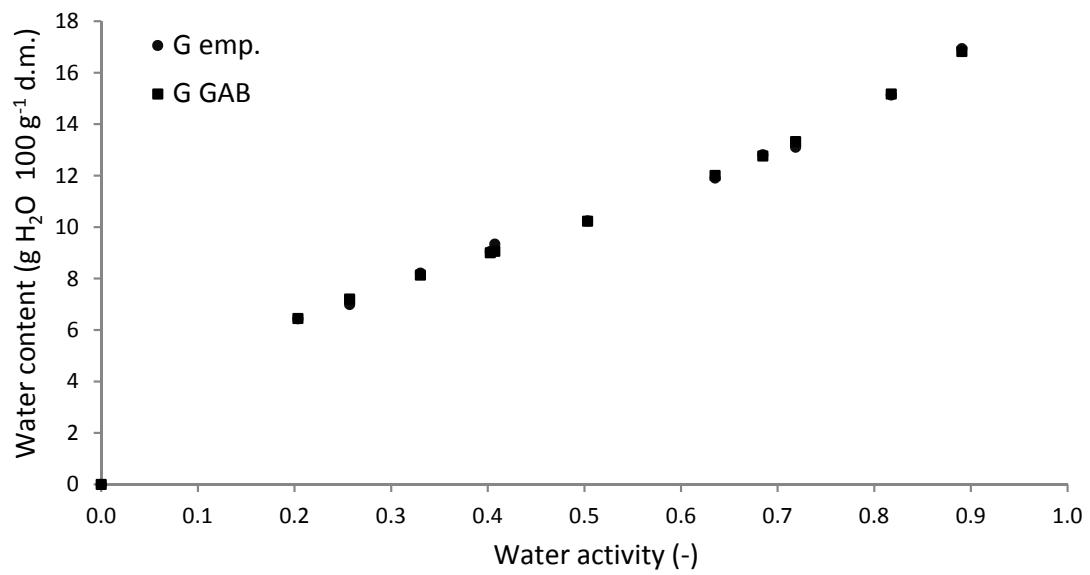

b

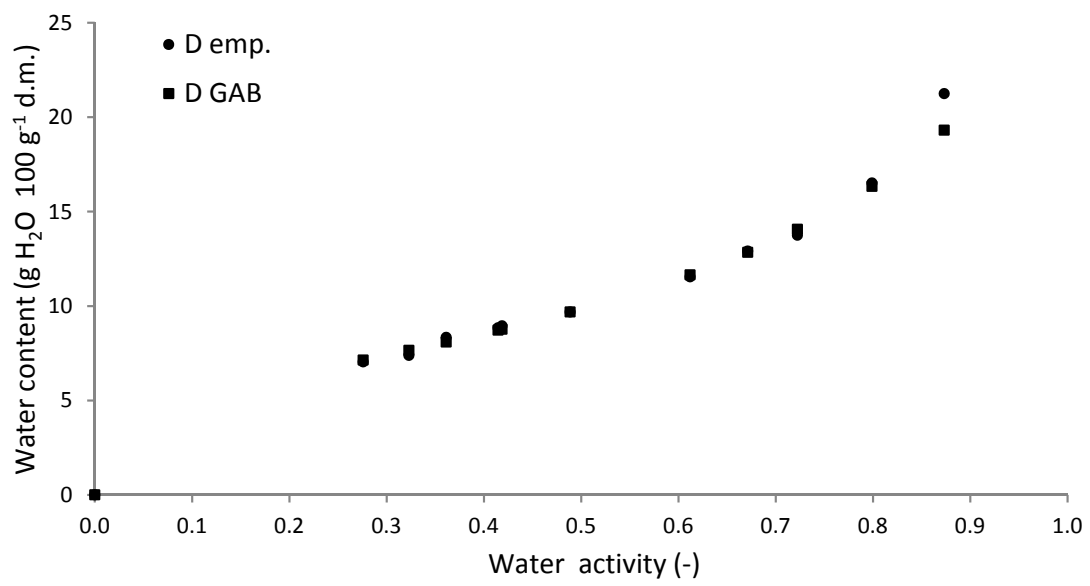

Fig. 3. Empirical and theoretical $(G A B)$ water vapour adsorption isotherm of samples: $a-G$ and $b-D$.

Table 3. The GAB equation parameters of black pepper samples and $a_{w}$ corresponding to $v_{m}$

\begin{tabular}{lcc}
\hline Parameters & Product G & Product D \\
\hline SSD (-) & $0.208 \pm 0.161$ & $0.338 \pm 0.220$ \\
RMS (\%) & 1.4775 & 3.3212 \\
$v_{m}\left(\mathrm{~g} \mathrm{H}_{2} \mathrm{O} 100 \mathrm{~g} \mathrm{~g}^{-1}\right.$ d.m.) & $8.028 \pm 0.270$ & $6.410 \pm 0.367$ \\
$K(-)$ & $0.612 \pm 0.016$ & $0.772 \pm 0.025$ \\
$C_{G}(-)$ & $16.60 \pm 2.01$ & $26.17 \pm 12.72$ \\
\hline
\end{tabular}

The value of $K$, a constant, which corrects the properties of molecules forming the multilayer as compared to the liquid phase, took on values ranging from $0.6125 \pm 0.0157(\mathrm{G})$ to $0.7718 \pm 0.0248$ (D) (Table 3 ). The obtained results indicate that this equation was appropriately used to describe the experimental data, since Lewicki (1997) demonstrated that one of the conditions for the correct application of the GAB equation to describe the experiment is the $K$ value falling within the range of 0.24 to 1 . Where the numerical value of the constant $K$ falls within the indicated range, maintaining the error of calculation of the water content of the monolayer at a level of $\pm 15.5 \%$ requires a numeri- cal value of the constant $C_{G}$ greater than 5.5. Moreover, according to Caurie (2006), the $K$ value enables the differentiation of monomolecular $(K \leq 0.5)$ and multilayer $(K>0.5)$ adsorption. On the other hand, Chirife and Iglesias (1992) concluded that the $K$ value is determined by the type of the product being described. Where absorption occurs on the surface of protein structures, the $K$ parameter values fall within the range of 0.82 to 0.86 , while for starch structures they ranged from 0.7 to 0.77 . On the other hand, PérezAlonso et al. (2006) indicated that for products in which the sorption properties are largely determined by proteins, the $K$ constant values fall within a wider range of 0.84 to 1.00 , while for the dominant role of fibre, the $K$ constant takes on values ranging from 0.717 to 0.893 . Taking into account the specificity of the analysed material, the obtained $K$ values should be regarded as the result of interactions occurring during the absorption of water molecules by the heterogenous structure of ground pepper grains rather than a simple result of the interactions occurring between proteins and starch. Therefore, the sorption properties of the analysed black pepper samples of different fineness levels 
were determined by the significant percentage of the starch fraction as well as by their physical diversity related to the fineness level.

Based on the previously calculated GAB equation parameters or, more precisely, the extension of the monolayer $\left(v_{m}\right)$ and the range of points describing the adsorption isotherms in the area of capillary condensation, selected parameters of the surface microstructure of the black pepper samples of different fineness levels were evaluated (Table 4).

Large-particle pepper $(\mathrm{G})$ was characterized by a greater sorption specific surface area than very fine-particle pepper (D), which may intuitively appear to be contrary to

Table 4. Structural characteristics of the tested products

\begin{tabular}{ccc}
\hline $\begin{array}{c}\text { Specific surface } \\
\text { of sorption } a_{s p} \\
\left(\mathrm{~m}^{2} \mathrm{~g}^{-1} \text { d.m. }\right)\end{array}$ & $\begin{array}{c}\text { General capacity of } \\
\text { capillaries } \\
\left(\mathrm{mm}^{3} 100 \mathrm{~g}^{-1} \text { d.m. }\right)\end{array}$ & $\begin{array}{c}\text { Capillary radius } \\
\text { at } a_{w}=0.65(\mathrm{~nm})\end{array}$ \\
\hline \multirow{3}{*}{282} & Product G \\
& 65.48 & 1.48 \\
225 & Product D & \\
& 67.28 & 1.50 \\
\hline
\end{tabular}

a

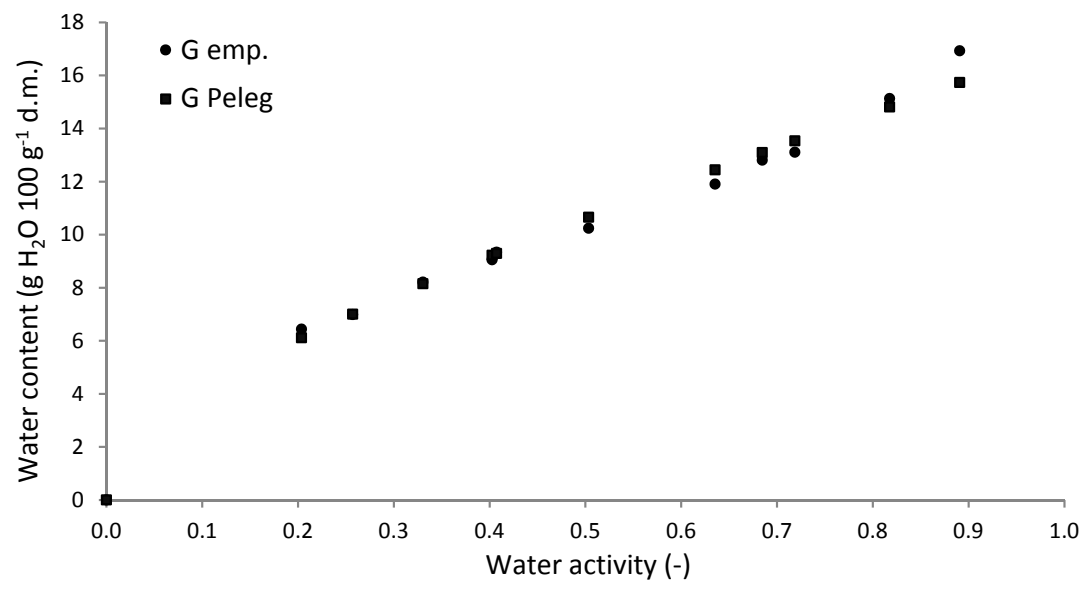

$\mathrm{b}$

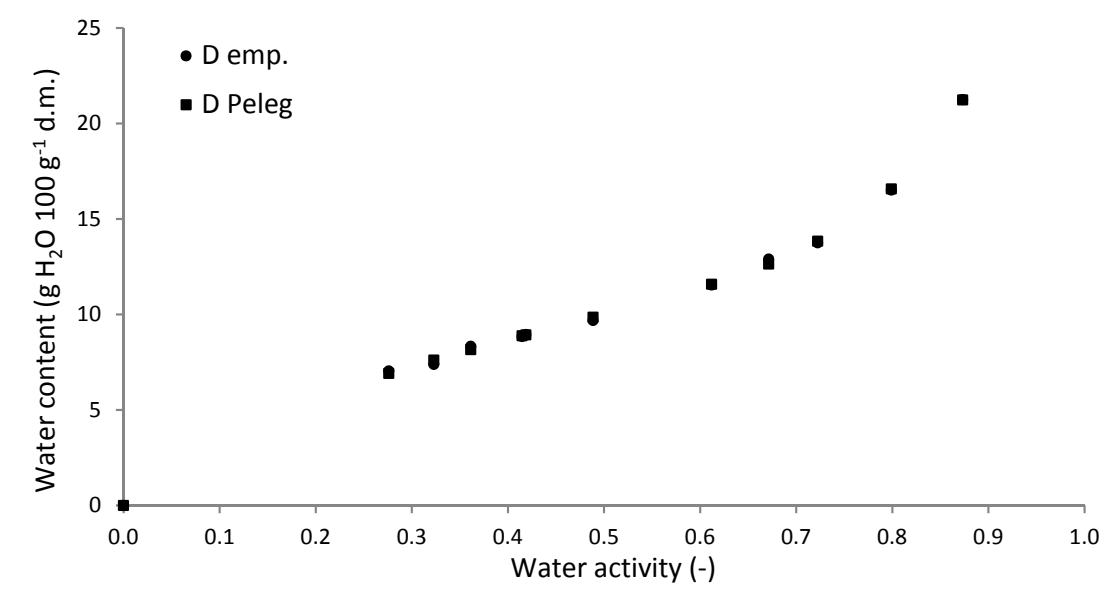

Fig. 4. Empirical and theoretical (Peleg) water vapour adsorption isotherm of samples: $a-G$ and $b-D$. expectations. This is because the grinding process results in a significant expansion of the specific surface area, which usually contributes to an increase in the dynamics of surface phenomena related to the effects of water vapour, which is referred to as hygroscopicity. As a result of grinding, pepper should become a highly hygroscopic product, due to the increase in the area of contact with the environment and a significant reduction in water content during the grinding process, which is accompanied by an increase in temperature that promotes drying. At the same time, it should be stressed that in the process of pepper grinding, the starch matrix (characterized by an ordered, crystalline structure) is primarily expanded. This, in turn, does not necessarily result in a significant increase in sorptivity. It should also be noted that large-particle pepper $(G)$ was characterized by a higher content of water which, by interacting with the protein fraction, may bring about structural changes in this fraction that lead to the exposure of new, previously hidden hydrophilic groups and thus contribute to an increase in the specific sorption surface. The presence of water in a product measurably contributes to shaping its quality (the product's characteristics) which may be perceived in the context of inter alia hygroscopicity or stability during storage.

F. 4 . Empinical and theoretical (Peleg) water vapour adsorption isotherm of samples: $a-G$ and $b-D$. 
The data generated based on the GAB model were also used to calculate the general capillary capacity of the tested material as the total volume of water adsorbed by the material within the water activity range of 0.65 to 0.93 was due to the model's usefulness in describing sorption curves within a range wider than that of the BET model (Figura and Teixeira, 2007; Ocieczek, 2012). It was demonstrated that irrespective of the pepper fineness level, the surface structure did not differ significantly in terms of porosity, which was reflected in the comparable values of the general capillary capacity (Table 4). At the same time, under conditions initiating capillary condensation, capillaries of a similar radius were filled on the surface of the pepper particles irrespective of the fineness level.

In summary, it may be assumed that the size of pores as reflected by their radius was the factor determining the general capillary capacity of the analysed products. The same conclusions were reached by Ocieczek and Ruszkowska (2018) in a study concerning the sorptivity of quinoa seeds. The simultaneously obtained results indicate that irrespective of the pepper fineness level, its particle surface structure is similar. This, in turn, may be interpreted as evidence of the dominant role of the starch fraction with an ordered structure in shaping the sorption properties of ground pepper and the significant role of water in the modification of the surface structure through its interaction with the hydrophilic protein fraction.

In order to describe the sorption isotherms of pepper of different fineness levels, the four-parameter Peleg model was also applied. Figures $4 \mathrm{a}$ and $\mathrm{b}$ show the course of the sorption isotherms for both tested black pepper samples, empirically determined and theoretically calculated based on the Peleg equation. This model is described as an empirical equation devoid of a theoretical background (Andrade et al., 2011). The results of numerous studies, including this paper, indicate that the Peleg model exhibits a similar usefulness for describing water vapour sorption as that of the GAB model (Table 5).

Table 5. Peleg's equation parameters

\begin{tabular}{ccc}
\hline Parameters & Product G & Product D \\
\hline SSD (-) & $2.4032 \pm 0.6329$ & $0.2161 \pm 0.1898$ \\
RMS (\%) & 3.5222 & 1.5306 \\
$A$ & $8.39 \pm 1.92$ & $15.22 \pm 0.55$ \\
$B$ & $0.40 \pm 5.80$ & $0.61 \pm 0.04$ \\
$D$ & $8.71 \pm 1.92$ & $23.66 \pm 2.22$ \\
$E$ & $1.03 \pm 9.13$ & $8.76 \pm 0.97$ \\
\hline
\end{tabular}

The RMS values of the sorption isotherm estimation using the Peleg model ranged from 1.53 to $3.52 \%$, which proves that the model described the experimental data very well, irrespective of the differences in the course of the surface absorption phenomenon, which are determined by the physical diversity of the analysed pepper samples. A comparison with Peleg's equation parameters indicates that the analysed pepper samples differed significantly from each other in terms of their sorption properties.

A comparison of the statistics used to assess the predictive power of particular models allowed for an unequivocal demonstration that both the GAB and Peleg models met the criterion of a very good model fit to the experimental data. Moreover, taking into account the theoretical nature of the GAB model, one may indicate its greater usefulness by conducting research into the surface phenomena occurring in dehydrated food, which determine its storage stability.

\section{CONCLUSIONS}

1. Isotherms of water vapour sorption on the surface of black pepper particles of different fineness levels were characterized by a course typical of the type II isotherm according to the Brunauer classification.

2. Commercial samples of black pepper of different fineness levels ( $G$ and $D$ ) were characterized by water contents, which varied to a statistically significant extent, the content of water was determined by its activity and was probably the main reason for the differentiation of the sorption properties of the samples. Pepper with a low fineness level exhibited a higher monomolecular layer volume and, consequently, a greater sorption specific surface area. The analysed pepper samples did not differ significantly in terms of porosity or capillary capacity.

3. The GAB and Peleg models described the empirically determined sorption isotherms of ground black pepper very well within the full range of water activity. The calculated root mean square for these models oscillated at a level, which was undoubtedly lower than $10 \%$.

Conflict of interest: The Authors do not declare conflict of interest.

\section{REFERENCES}

Ahlneck C. and Zografi G., 1990. The molecular basis of moisture effects on the physical and chemical stability of drugs in the solid state. Int. J. Pharm., 62, 87-95. https://doi.org/10.1016/0378-5173(90)90221-o

Akanbi C.T., Adeyemi R.S., and Ojo A., 2006. Drying characteristics and sorption isotherm of tomato slices. J. Food Eng., 73(2), 157-163. https://doi.org/10.1016/j.jfoodeng.2005.01.015

Al-Muhtaseb A.H., McMinn W.A.M., and Magee T.R.A., 2002. Moisture sorption isotherm characteristics of food products: A review. Food Bioprod. Process., 80(2), 118-128. https://doi.org/10.1205/09603080252938753 
Andrade R.D., Lemus R.M., and Pérez C.C., 2011. Models of sorption isotherms for food: uses and limitations. Vitae, J. Faculty of Pharmaceutical Chemistry, 18(3), 325-334.

Babetto A.C., Freire F.B., Barrozo M.A.S., and Freire J.T., 2011. Drying of garlic slices: Kinetics and nonlinearity measures for selecting the best equilibrium moisture content equation. J. Food Eng., 107, 347-352. https://doi.org/10.1016/j.jfoodeng.2011.07.007

Buckton G., 1997. Characterisation of small changes in the physical properties of powders of significance for dry powder inhaler formulations. Adv. Drug Deliv. Rev., 26, 17-27. https://doi.org/10.1016/s0169-409x(97)00507-3

Caurie M., 2006. The derivation of the GAB adsorption equation from the BDDT adsorption theory. Int. J. Food Sci. Technol., 41(2), 173-179. https://doi.org/10.1111/j.1365-2621.2005.01044.x

Chirife J. and Iglesias H.A., 1992. Estimation of precision of isosteric heat of sorption determined from the temperature dependence of food isotherms. LWT, 25(1), 83-84.

Chowdhury M.M.I., Huda M.D., Hossain M.A., and Hassan M.S., 2006. Moisture sorption isotherms for mungbean (Vigna radiata L). J. Food Eng., 74, 462-467. https://doi.org/10.1016/j.jfoodeng.2005.03.036

Diosady L.L., Rizvi S.S.H., Cai W., and Jagdeo D.J., 1996. Moisture sorption isotherms of canola meals, and applications to packing. J. Food Sci., 61, 204-208. https://doi.org/10.1111/j.1365-2621.1996.tb14760.x

Figura L.O. and Teixeira A.A., 2007. Food Physics. Physical Properties, Measurement and Applications. SpringerVerlag, Berlin Heidelberg.

Gal S., 1983. The need for, and practical applications of sorption data. In: Physical Properties of Foods (Eds R. Jowit, F. Escher, B. Hallstrom, H.F.T. Meffert, W.E.L. Spiess, G. Vos). Applied Science Published, New York.

Gondek E. and Lewicki P.P., 2005. Moisture sorption isotherms of dried and candided fruits (in Polish). Acta Sci. Pol., Technol. Aliment., 4(1), 63-71.

Karel M., 1975. Water activity and food preservation. In: Physical Principles of Food Preservation. Principles of Food Science. Part 2 (Eds M. Karel, O.R. Fennema. D.B. Lund). Marcel Dekker, New York. https://doi.org/10.1201/9780203911792

Lewicki P.P., 1997. The applicability of the GAB model to food water sorption isotherms. Int. J. Food Sci. Technol., 32(6), 553-557. https://doi.org/10.1111/j.1365-2621.1997.tb02131.x

Lewicki P.P., 2006. Design of hot air drying for better foods. Food Sci. Technol., 17, 153-163. https://doi.org/10.1016/j.tifs.2005.10.012

Newman A. and Zografi G., 2019. An examination of water vapor sorption by multicomponent crystalline and amorphous solids and its effects on their solid-state properties. J. Pharmaceutical Sci., 108, 1061-1080. https://doi.org/10.1016/j.xphs.2018.10.038
Ocieczek A., 2012. Hydration properties of machine wheat flours as a discriminant of the usable quality (in Polish). Scientific Works of the Gdynia Maritime University, Gdynia, Poland.

Ocieczek A. and Kostek R., 2009. Sorptive properties of type 2000 wheat and rye flours. Acta Agrophysica, 14(2), 393-402.

Ocieczek A. and Ruszkowska M., 2018. Comparing sorption properties of grains of selected Quinoa Varieties (Chenopodium quinoa Willd.) (in Polish). Żywność, Nauka, Technologia, Jakość, 25, 3(116), 71-88.

Palacha Z. and Sas A., 2016. Sorption properties of selected species of rice (in Polish). Acta Agroph., 23 (4), 681-694.

Pérez-Alonso C., Berstain C.I., Lobato-Calleros C., RodriguezHuezo M.E., and Vernon-Carter E.J., 2006. Thermodynamic analysis on the sorption isotherms of pure and blended carbohydrate polymers. J. Food Eng., 77(4), 753760. https://doi.org/10.1016/j.jfoodeng.2005.08.002

Rizvi S.S.H., 1995. Thermodynamic properties of food in dehydration. In: Engineering Properties of Foods (Eds M.A. Rao, S.S.H. Rizvi). Marcel Dekker Inc., New York-BaselHong Kong.

Roman G.N., Urbicain M.J., and Rotstein E., 1982. Moisture equilibrium in apples at several temperatures. Experimental data and theoretical considerations. J. Food Sci., 47, 1484-1492. https://doi.org/10.1111/j.1365-2621.1982.tb04966.x

Roos Y.H., 1995. Phase transitions in foods. CA: Academic Press San Diego.

Sacilik K. and Unai G., 2005. Dehydration characteristics of Kastamonu garlic slices. Biosys. Eng., 92(2), 201-215. https://doi.org/10.1016/j.biosystemseng.2005.06.006

Sahin S. and Gülüm S., 2006. Physical properties of foods. New York, United States: Springer.

Slade L. and Levine H., 1991. Beyond water activity: Recent advanced based on alternative approaches to the assessment of food quality and safety. Critical Reviews in Food Science and Nutrition, 30, 115-360.

https://doi.org/10.1080/10408399109527543

Timmermann E.O., Chirife J., and Iglesias H.A., 2001. Water sorption isotherms of food and foodstuffs: BET Or GAB parameters? J. Food Eng., 48, 19-31. https://doi.org/10.1016/s0260-8774(00)00139-4

Triwahyudi S., Rahardjo B., Nelwan L.O., and Wulandani D., 2015. Mathematical modeling of equilibrium moisture content of local cardamon (Amomum cardamomum Wild). Int. J. Scientific Eng. Technol., 4, 2, 40-44. https://doi.org/10.17950/ijset/v4s2/203

Tsami E., Marinos-Kouris D., and Maroulis Z.B., 1990. Water sorption isotherms of raisins, currants, figs, prunes and apricots. J. Food Sci., 55, 1594-1597. https://doi.org/10.1111/j.1365-2621.1990.tb03578.x 